\title{
REDES NEURAIS APLICADA NA AUTOMAÇÃO DE UMA RESIDÊNCIA ENERGETICAMENTE EFICIENTE
}

\author{
F. Franco. Muriel ${ }^{1}$, P. Ferrugem. Anderson ${ }^{2}$, B. Silveira. Antônio César ${ }^{3}$ \\ ${ }^{1}$ Grupo de Aplicações em Inteligência Artificial, Universidade Federal de Pelotas \\ (mffranco@inf.ufpel.edu.br)
}

${ }^{2}$ Centro de Desenvolvimento Técnológico, Universidade Federal de Pelotas (ferrugem@inf.ufpel.edu.br)

${ }^{3}$ Laboratório de Conforto e Eficiência Energética, Faculdade de Arquitetura de Urbanismo da Universidade Federal de Pelotas (acsbs@uol.com.br)

Resumo. Este trabalho tem como objetivo a criação de um controle utilizando técnicas de inteligência artifical aplicado na automação de uma residência energeticamente eficiente. A rede neural é uma técnica da inteligência artificial que visa trabalhar no processamento de dados de maneira semelhante ao cérebro humano. Com a rede neural podemos criar um controle inteligente para a abertura e fechamento de janelas existentes em uma construção a fim de estabelecer no interior da residência um estado de conforto térmico, onde a temperatura mantenha-se agradável ao ser humano sem a necessidade da utilização de equipamentos que causem danos ao meio ambiente.

Keywords: Inteligência Artificial, Redes Neurais, Eficiência Energética, Automação Residencial

\section{INTRODUÇÃO}

Este trabalho visa a utilização de redes neurais na automação de uma residência energeticamente eficiente. A rede neural é uma técnica da inteligência artificial que busca trabalhar no processamento de dados de maneira semelhante ao cérebro humano, pode ser interpretada como um esquema de processamento capaz de armazenar conhecimento baseado em aprendizagem e disponibilizar esse conhecimento para a aplicação em questão. [2]

Ao utilizar a rede neural é possivel criar um controle eficaz para realizar a abertura e fechamento das janelas existentes em uma residência a fim de estabelecer um estado de conforto térmico no interior da construção, tendo como base para o ambiente estar agradável ao ser humano o Voto Médio Estimado(PMV) descrito por Fanger, que traduz a sensibilidade humana ao frio e a calor em um valor numérico [1], podendo variar entre o intervalo de -3 a 3. Quanto mais aproxima-se de zero melhor é o conforto térmico do ambiente. O cálculo do PMV baseia-se nas seguintes variáveis: temperatura média radiante, velocidade do ar, umidade relativa, temperatura do ar, atividade física e vestimenta dos indivíduos da região. 


\section{METODOLOGIA}

A residência foi construida virtualmente utilizando o Design Builder, após modelada a residência é gerado um Input Data File(IDF) esse arquivo é usado como entrada para o Energy Plus, ele possui dados detalhados da construção. O Energy Plus é uma ferramenta desenvolvida para a avaliação do desempenho do edifico, com ela é possivel simular os sistemas de aquecimento, iluminação e ventilação, de forma a quantificar seu consumo de energia.

Foi utilizado o Building Virtual Test Bed(BCVTB), o qual possibilita a conexão em tempo de simulação entre modelos desenvolvidos através do Energy Plus e outros softwares. O Matlab foi escolhido para ser desenvolvido o controle por já possuir módulos implementados para redes neurais multicamadas backpropagation, chamada Neural Toolbox.

Com a interface do BCVTB fazendo a conexão entre o Energy Plus e o Matlab tornou possivel o desenvolvimento um controle com redes neurais para ser aplicado durante a simulação da casa, de modo que simulasse uma interação real com a casa.

Figura 1. Interface do BCVTB fazendo a conexão entre os softwares

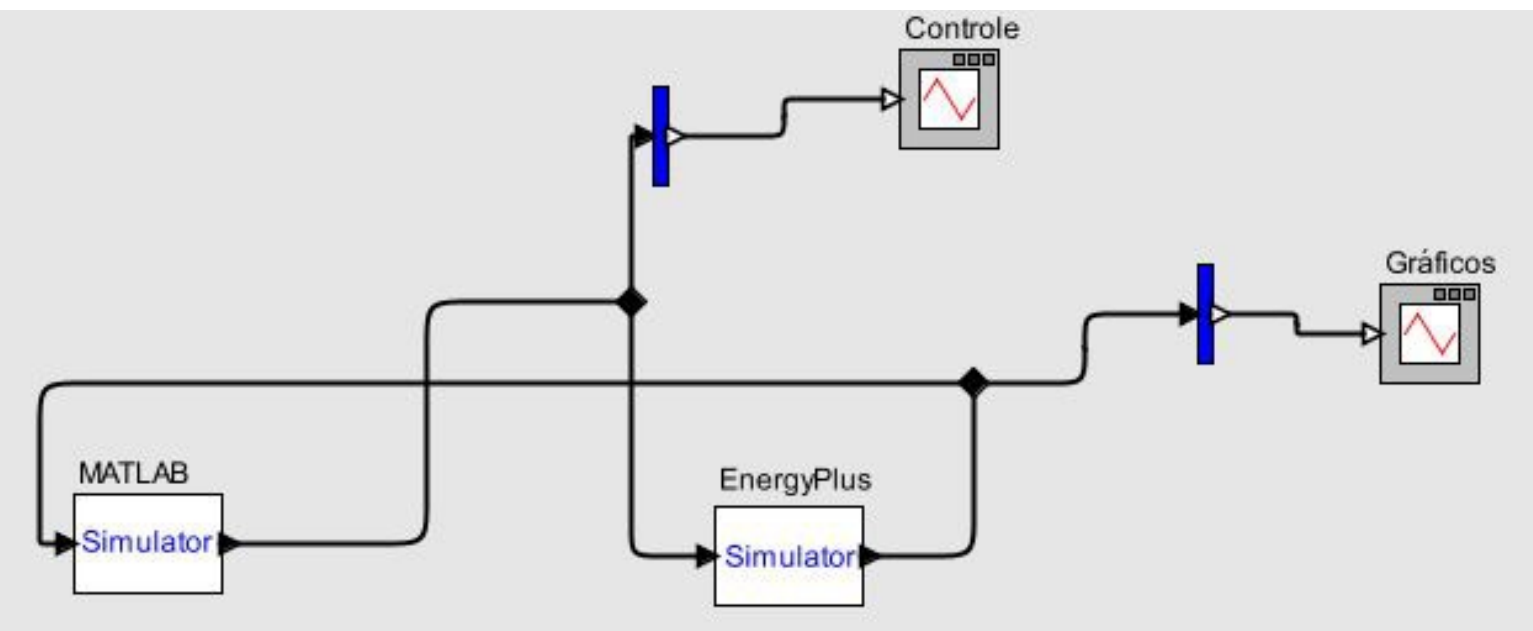

Foi usado a definição de rede neural multicamada backpropagation, técnica que consiste no reajuste dos pesos da rede, onde os pesos são ajustados na ordem contrária a cada propagação, utilizando como base os valores encontrados na camada de saida e o valor esperado[2]. Este modelo foi selecionado como referência por se tratar de um modelo simples e atender todas as necessidades requeridas quanto a capacidade de aprendizado.

Nossos dados para treinamento da rede neural foram obtidos através de diversas simulações, onde foram verificado os efeitos da abertura e fechamento das janelas em todas horas do dia, durante um mês inteiro. Os resultados obtidos foram dividos em dois grupos denominados respectivamente entrada e saída, os dados climáticos 
como temperatura externa, ponto de orvalho, direção e difusão solar, velocidade e direção do vento, umidade do ar e pressão atmosférica são as entradas, e os estados das janelas definidos como aberto e fechado que obtiveram menor pmv com os dados climáticos atuais são as saídas para o aprendizado da rede.

O treinamento da rede neural se dá através de uma função da ferramenta Neural Network Toolbox disponibilizada pelo Matlab chamada newff, função que cria uma rede neural backpropagation. Com a rede já treinada e disponivel para o controle iniciamos a simulação aplicando o conhecimento adquirido no treinamento, A residência é simulada no Energy Plus e seus dados enviados para o Matlab que utiliza aplica o controle a fim de definir o melhor estado das janelas para o determinado momento, os dados resultantes após a aplicação da melhor sequência de janelas é enviado ao Energy Plus novamente, este processo se repete durante todas horas e dias de um mês previamente definidos.

\section{RESULTADOS}

Ao terminar a simulação obtivemos um PMV dentro da faixa de conforto térmico(-3 a 3) e próximo de zero, isso indica que foi obtido melhoras consideráveis no controle utilizando redes neurais, conseqüência do controle aplicando a abertura e fechamento das janelas conforme o conhecimento adquirido pela rede neural.

A definição da rede multicamada backpropagation se mostrou uma boa opção para nosso controle, sua simplicidade e capacidade de aprendizado nos permitem a partir de então criar controles mais complexos mantendo-a como referência.

Com o controle criado implementaremos outras técnicas de inteligência artificial como lógica difusa e também um controlador PID a fim de verificar qual alcança melhores resultados.

\section{CONCLUSÃO}

Com base na implementação e simulação realizada podemos observar que foi fundamental a utilização da rede neural para aproximar-se do conforto térmico e com isso criar um controle bastante eficiente e simples que nos permite no futuro economizar energia na utilização de equipamentos de ventilação e aquecimento apenas controlando a abertura e fechamento das janelas durante o dia e noite de modo que a temperatura ambiente seja sempre agradável ao ser humano. Com os resultados satisfatórios do controle obtidos através das redes neurais, poderemos no futuro criar novas regras de controle e utilizar outras técnicas de inteligência artificial como lógica difusa e também fazer a implementação de um controlador PID a fim de alcançar o conforto térmico. 


\section{REFERÊNCIAS}

[1] Fanger, O. Thermal Comfort - Analysis and application in environmental engineering. Copenhagen, 244 p., 1970

[2] HAYKIN, Simon. Redes Neurais: Princípios e Práticas. 2 ed, 900p., 2007.

[3] LAMBERTS, R. Dutra, L., Pereira, F.O.R., Eficiência Energética na Arquitetura. Universidade Federal do Rio Grande do Sul, Laboratório de Conforto Ambiental, 1997

[4] ABREU, Ana Lígia Papst de. Método Estimativo da Temperatura Interna de Edificações Residenciais em Uso. Florianópolis, 2004.

[5] LUGER, George F. Inteligência Artificial: Estruturas e Estratégias Para a solução. 4 ed., 776 p., 2004.

[6] MEDVEDOVSKI, Eduardo. Técnicas de inteligência artificial aplicadas a um dispositivo de aquecimento natural para ambientes. 2010. Dissertação - Bacharelado em Ciência da Computação - CDTEC, Universidade Federal de Pelotas, Pelotas, Dezembro. 